\title{
Breast Benign Papillary Lesions: Mini-Review
}

\author{
Shinya $\mathrm{T}^{1 *}$, Ichiro $\mathrm{M}^{1}$, Motohiro $\mathrm{C}^{1}$, Keiko $\mathrm{K}^{2}$, Takafumi $\mathrm{O}^{2}$, Koichiro \\ $\mathrm{T}^{3}$ and Masayuki $\mathrm{T}^{1}$ \\ ${ }^{1}$ Department of Pathology, St. Marianna University School of Medicine, Japan \\ ${ }^{2}$ Department of Radiology, St. Marianna University School of Medicine, Japan \\ ${ }^{3}$ Department of Breast and Endocrine Surgery, St. Marianna University School of \\ Medicine, Japan
}

*Corresponding author: Shinya Tajima, Department of Pathology, St. Marianna University School of Medicine, 2-16-1

Sugao, Miyamae-ku, Kawasaki city, Kanagawa prefecture, 216-8511, Japan, Tel: +81-44-977-8111 (3140); Fax: +81-44-

977-7827; Email: stajima0829@gmail.com

\section{Mini Review}

Breast papillary lesions are divided into a broad spectrum including benign intraductal papilloma (IDP), radial sclerosing lesions (RSL), subareolar sclerosing duct hyperplasia, cystic and papillary apocrine metaplasia, florid papillomatosis of the nipple, syringomatous adenoma of the nipple, collagenous spherulosis, atypical ductal hyperplasia (ADH), ductal carcinoma in situ (DCIS), encapsulated papillary carcinoma (EPC), and invasive papillary carcinoma [1].

As mentioned above, breast papillary lesions are consist of benign, tumor of uncertain malignant potential (indeterminate), and malignant. Hence, accurate diagnosis between benign and malignant is important in breast papillary lesions. And, the most common breast papillary lesion is intraductal papilloma. Papillomas are discrete benign tumors of the epithelium of mammary ducts with the presence of myoepithelial cells. These lesions arise more often in the central part of the breast from lactiferous ducts, however papillomas may occur periphery. This lesion is called peripheral papilloma. Intraductal papilloma is associated with a risk of carcinoma in $7 \%$ of woman of less than 60 years of age and in $30 \%$ of those of more than 60 years of age [2]. Furthermore, it is known that some intraductal papillomas accompanied by malignant lesion.

To differentiate between benign and malignant lesion in breast papillary lesion, it is reported that combination of high molecular weight cytokeratin (HWCK) of CK14 and estrogens (ER) immuno staining are useful. In using these immunostainings, almost all of the papillary lesions are diagnosed benign or malignant excluding apocrine papillary lesion. Furuya et al advocated the Differential Index using Allred Score: ([ER total score] + [MUC3 total score]) / ([CK5/6 total score] + [p63 total score]) [2]. If this score is less than 1 , it is thought that it is benign lesion. This formula is useful discriminating between benign and malignant papillary lesions, if CK14 and ER are not available.

Loss of myoepithelial cells in breast tumors are commonly thought to be malignant and invasive lesions. In the past, Cserni $\mathrm{G}$ and Tram $\mathrm{T}$ et al. reported that benign and non-invasive apocrine papillary lesions which show reduction and occasional complete loss of myoepithelial cells $[3,4]$. These lesions are thought to be benign lesion, however lack of myoepithelial cells. And apocrine papillary lesions are considered to be distinct lesions. Recently, Shinya et al. reported that the two cases of non-apocrine papillary lesions lacking myoepithelial cells [5]. These lesions showed epithelial papillary proliferation with nuclear inverse polarity, absence of nuclear atypical lined by the fibro vascular core, and lack of myoepithelial cells. In immunostainings, CK14 and ER were both negative. Hence, they tried the differential index, and the lesions were considered to be benign. 
In conclusion, breast papillary lesion is sometimes difficult to distinguish benign from malignant. And the lack of myoepithelial cells in papillary lesions does not necessarily indicate malignancy. We have to diagnose the breast papillary lesions attentively.

\section{References}

1. Rosen PP (2008) Papilloma and related benign tumors. Rosen's Breast Pathology, pp: 85-136.

2. Furuya C, Kawano H, Yamanouchi T, Oga A, Ueda J, et al. (2012) Combined evaluation of CK5/6, ER, p63, and MUC3 for distinguishing breast intraductal papilloma from ductal carcinoma in situ. Pathol Int 62(6): 381-390.
3. Tramm T, Kim JY, Tavassoli FA (2011) Diminished Number of Complete Loss of Myoepithelial Cells Associated with Metaplastic and Neoplastic Apocrine Lesions of the Breast. Am J Surg Pathol 35(2): 202211.

4. Cserni G (2008) Lack of myoepithelium in apocrine glands of the breast does not necessarily imply malignancy. Histopathology 52(2): 263-255.

5. Tajima S, Maeda I, Aida Y, Kazama A, Koizumi H, et al. (2018) Nuclear inverse polarity papillary lesions lacking myoepithelial cells: A report of two cases. Pathol Int 68(1): 36-40. 